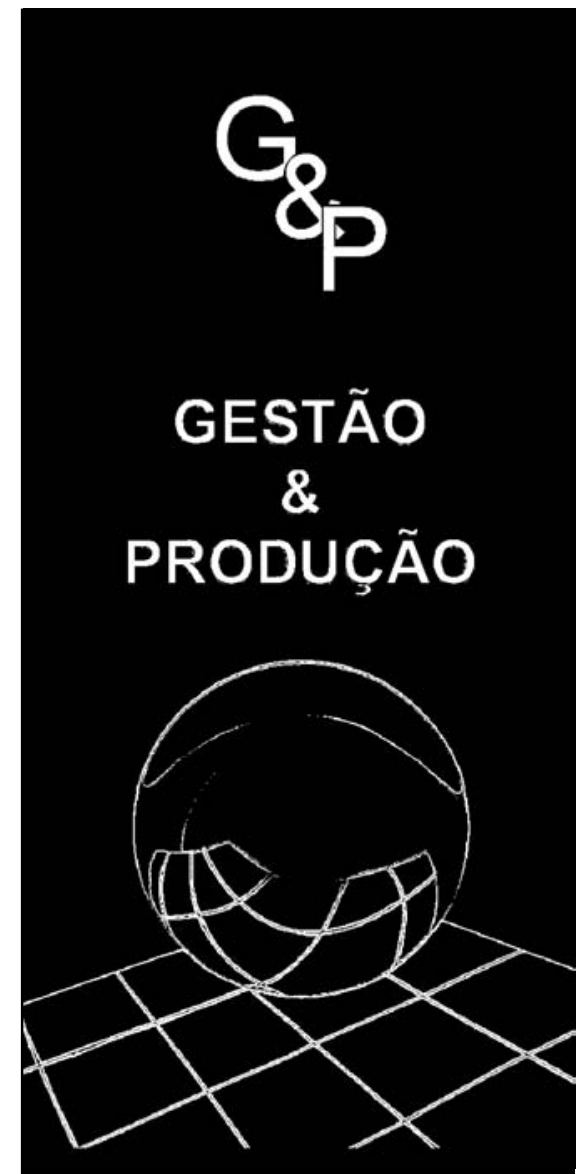

v.8, n.1, p. 37-55, abr. 2001

\section{TÉCNICAS DA PESQUISA OPERACIONAL APLICADAS NA OTIMIZAÇÃO DOS SERVIÇOS POSTAIS}

\author{
Deise Maria Bertholdi Costa* \\ Maria Teresinha Arns Steiner** \\ Celso Carnieri** \\ Luzia Vidal S. Zamboni* \\ Arinei C. Lindbeck da Silva** \\ Universidade Federal do Paraná \\ Departamentos: *Desenho e ** Matemática \\ Caixa Postal 19081 - CEP 81531-900 - Curitiba - PR \\ E-mails: deise@cce.ufpr.br, tere@mat.ufpr.br, \\ carnieri@mat.ufpr.br, luzia@cce.ufpr.br
}

\title{
Resumo
}

O presente trabalho apresenta uma metodologia para a otimização do serviço de entrega de correspondências realizado pela Empresa de Correios e Telégrafos (ECT) a partir da aplicação de algumas técnicas da Pesquisa Operacional. Como o serviço de entrega e as etapas que o antecedem (separação e ordenação dos objetos) são realizadas manualmente, existe a necessidade de otimizá-las e isto é possivel redefindo-se as regiões de atendimento para cada carteiro. Para tanto, o problema foi tratado como um problema de roteamento de veículos. Vários algoritmos clássicos foram utilizados; inicialmente para definir as áreas de atendimento dos carteiros, chamados de distritos postais e, a seguir, para estabelecer o roteiro de entrega das correspondências, considerando, nesta fase, as distâncias reais entre os pontos de entrega. Vários testes computacionais foram realizados, variando-se os algoritmos e parâmetros iniciais e suas respostas comparadas através das distâncias totais e de tempos computacionais, determinando-se, assim, os algoritmos com melhores desempenhos.

Palavras-chave: problema de roteamento de veículos, clusters e rotas ótimas.

\section{Introdução}

volume de objetos (correspondências, encomendas, etc.) entregue pela empresa estatal ECT-Correios tem aumentado em média, na cidade de Curitiba, de 10 a $15 \%$ ao ano, sendo que a mesma não pode efetuar novas contratações. Com a falta de funcionários 
ocorrem os atrasos na entrega das correspondências. Como o maior custo da empresa está na área de distribuição domiciliar, em torno de 40 a $45 \%$ do custo total, existe, então, a necessidade de melhorar o processo de entrega, que é composto, basicamente, da separação, ordenação e entrega dos objetos, etapas estas que são realizadas pelos próprios carteiros. Isto é possível, estabelecendo-se adequadamente áreas de atendimento para cada carteiro e fornecendo roteiros de entrega otimizados.

Pretende-se, neste trabalho, estabelecer um procedimento de solução para a entrega de objetos pelos serviços postais com os seguintes objetivos: determinar novas áreas de atendimento para entrega de correspondências para cada carteiro (denominada de Distrito Postal do carteiro - DP), considerando que a carga transportada seja aproximadamente a mesma para todos e, obter para cada carteiro o roteiro otimizado de entrega dos objetos dentro de seu distrito postal.

Para a solução da primeira fase do problema, da determinação dos distritos postais, foram utilizados algoritmos clássicos de solução do problema de roteamento capacitado de vários veículos e de vários depósitos. Vários testes foram realizados, variando-se parâmetros iniciais tais como: posição dos depósitos, capacidade máxima do veículo (no caso, carga máxima que o carteiro pode transportar), entre outros. Para o roteamento dos distritos postais, segunda fase do problema, foram testados vários algoritmos clássicos de solução do problema do caixeiro viajante, comparando-se os seus desempenhos em função do tempo computacional e de distâncias mínimas. As melhores soluções para estas duas fases foram identificadas e indicadas para comporem um procedimento de solução que pode ser aplicado a quaisquer outras regiões da cidade.

Como se trata de um problema de grande escala, com uma imensa quantidade de pontos de parada, houve a necessidade de utilizar uma linguagem de programação que possuísse a interação com um banco de dados, a fim de ser rápida a busca de informações. Os algoritmos foram programados na linguagem Visual Basic, utilizando as informações contidas num banco de dados. As respostas são dadas de duas maneiras: graficamente, podendo-se visualizar os distritos postais formados e as sequiências das rotas; e por meio de relatórios, indicando-se sequiências de atendimento, quantidade de pontos de parada, tempos computacionais e distâncias dos trajetos.

Alguns trabalhos relacionados ao problema abordado podem ser citados: no artigo Scheduling the postal carriers for the United States postal service, LEVY \& BODIN (1988) propuseram o roteamento de um carteiro dentro da sua área de atendimento, estabelecendo um programa de atendimento diário, não se preocupando com demanda, bem como com a divisão inicial da região entre os carteiros. Outros trabalhos similares: o problema da coleta de lixo (BELTRAMI \& BODIN, 1972); estabelecimento de frota para coleta de lixo urbano (CLARK \& GILLEAN, 1977); roteamento e scheduling de máquinas para varrer ruas (BODIN \& KURSH, 1978) e o problema da coleta de lixo urbano (NOGUEIRA et al., 1989).

Outras técnicas de solução para o problema de roteamento de veículos têm sido utilizadas. $\mathrm{O}$ problema da divisão de uma região em setores, por exemplo, pode ser tratado através do problema das p-medianas onde é utilizado um algoritmo para agrupamento de objetos (neste caso, são os pontos de parada) que leva em consideração além das distâncias euclidianas entre todos os pontos de parada, também um peso associado (podendo ser a demanda dos objetos) (MULVEY et al., 1984; BEZERRA, 1995). Outra proposta para a divisão de uma região em sub-regiões é colocada por DAGANZO (1984) e por GRACIOLLI (1996) que apresentam formulações para zoneamento, dividindo uma área em zonas, objetivando a minimização da distância média percorrida por ponto de parada, utilizando um algoritmo genético híbrido.

Para o problema de roteamento de veículos, podem-se citar várias meta-heurísticas, como por 
exemplo: algoritmos genéticos (MAYERLE, 1996; BEZERRA, 1995), busca tabu (COLORNI et al., 1996; GLOVER, 1989, 1990; GENDREAU et al., 1991; RIBEIRO, 1994; SOSA et al., 1996), simulated annealing (COLORNI et al., 1996; BARBOSA, 1989) e técnicas GRASP (Greedy Randomized Adaptive Search Procedure) (FEO et al., 1995). Estas meta-heurísticas, consideradas não determinísticas, tem como motivação evitar a obtenção de mínimos locais, mantendo temporariamente soluções ruins durante as iterações, com o objetivo de proporcionar a busca de soluções em outras vizinhanças, podendo fornecer soluções melhores do que as atuais já encontradas.

\section{Descrição do Processo de Entrega das Correspondências}

A função principal dos Correios, como prestadora de serviços de entregas, é de efetuar a distribuição de objetos tais como correspondências, encomendas, folhetos de propaganda, entre outros, aos devidos destinatários. Nesta seção será descrito o processo de separação e entrega dos objetos realizado pelos funcionários dos Correios enfatizando os problemas do processo.

Os Correios em Curitiba possuem um Centro de Triagem (CT) responsável pelo recebimento dos objetos da própria cidade e de outras localidades. O CT possui uma equipe de funcionários que faz o tratamento manual dos objetos selecionando-os de acordo com o destino, ou seja, pelo CEP (código de endereçamento postal), e encaminhando-os para os devidos locais (processo de primeira triagem). O CEP é um conjunto numérico constituído de oito algarismos, cujo objetivo principal é orientar e acelerar o tratamento, o encaminhamento e a distribuição de objetos, podendo identificar uma rua, um trecho de rua, um edifício, um órgão público, etc.

Os objetos que são entregues em Curitiba, estão codificados com os CEP's de oito dígitos variando de 80000-000 a 82999-999, sendo que esta numeração está subdividida em 12 faixas, cada uma das quais corresponde a uma região de Curitiba, formada por bairros da cidade. Em cada região os Correios possuem uma unidade responsável pela entrega de objetos, sendo denominada de Centro de Distribuição Domiciliar (CDD). Cada região abrangida por um CDD é ainda subdividida em distritos postais (DP) de acordo com o número de carteiros que trabalham na unidade. O DP de um carteiro é o seu local de entrega dos objetos, definindo, assim, a sua área de atendimento.

Para efetuar a entrega dos objetos nos devidos endereços dos usuários dos serviços postais, diariamente, o carteiro efetua a separação de sua carga de trabalho, que é realizada dentro da unidade do CDD (processo de segunda triagem). Esta tarefa é composta por uma triagem coletiva, uma individual e uma ordenação. Na triagem coletiva, da qual participam todos os carteiros, os objetos que chegaram do CT são separados de acordo com os distritos postais. Para tanto, cada carteiro deve saber identificar a qual DP pertence o objeto que ele está separando, ou seja, ele deve conhecer quais são os CEP's (ou as ruas) atendidos por seus colegas. Terminada esta fase, cada carteiro coleta os objetos relativos ao seu DP, e então começa a separar a sua própria carga, de acordo com os CEP's. Após esta triagem individual, ele faz a ordenação das correspondências para entrega (seqüência em que a correspondência será entregue) de acordo com o trajeto que irá percorrer. A seguir, o carteiro inicia seu trabalho externo, deslocandose até o ponto de início da entrega e percorrendo depois, a pé, de bicicleta ou moto, uma rede viária, composta de ruas pavimentadas ou não, os endereços dos usuários, denominados de pontos de parada, que obviamente não são os mesmos diariamente.

A região utilizada para este trabalho foi a atendida pelo CDD-Capão da Imbuia, o qual atende 5 bairros da cidade. Existem 28 carteiros trabalhando neste CDD, formando então os 28 distritos postais. A maioria dos distritos é muito afastada da sede do CDD, assim o carteiro, para chegar ao seu DP, utiliza um ônibus de linha e 
depois realiza a entrega dos objetos. Um dos grandes problemas desta região é a falta de seqüência na numeração dos pontos de entrega (das casas ou edifícios), ou ainda, a existência numa mesma rua de várias casas com a mesma numeração. As ruas em que isto ocorre são chamadas de ruas críticas.

Em 1993 foram coletadas informações sobre uma parte desta região (somente de um bairro), tais como: tempo gasto para percorrer um trecho de rua e para entregar as correspondências, quantidade de objetos a serem entregues, modo de fazer o trajeto (pode percorrer um lado do trecho, fazer o contorno no final do mesmo e retornar pelo outro lado - modo em U; pode percorrer o trecho cruzando a rua de um lado para o outro - modo em Z; pode percorrer apenas um lado da rua, pois o outro não há entregas - modo L). Após o levantamento destes dados, foi realizada a divisão da região em distritos postais, de maneira manual, pelos funcionários, tentando não dividir as ruas críticas entre os carteiros.

Outro problema é o aumento da quantidade de entregas. Nos últimos cinco anos, a quantidade de objetos entregues passou de 3,3 bilhões de objetos por ano para 6,2 bilhões de objetos por ano (CAMAROTTI, 1997). No CDD-Capão da Imbuia, o aumento do volume dos objetos para entrega elevou muito o tempo dispendido com o trabalho interno, prejudicando o trabalho externo. Em geral, o carteiro entrega apenas 70 ou $80 \%$ da carga total de seu CDD, deixando para o dia seguinte o que não pôde ser entregue no próprio dia, acumulando uma grande quantidade de objetos sendo entregues com atraso.

Algumas propostas, fornecidas pela própria ECT-Correios, estão sendo levantadas para melhorar o serviço de entrega dos objetos, tais como:

a) Perspectiva de triagem no CT pelos grupos de CEP's - no CDD-Capão da Imbuia, os cinco primeiros dígitos do CEP (que constituem o CEP5) variam dentro da faixa de 82800 a 82980, formando 12 subdivisões do CDD. A proposta dos Correios é que as correspon- dências já cheguem ao CDD separadas em conjuntos de CEP5. Assim, cada grupo de carteiros poderia se preocupar com a triagem de cada um dos conjuntos de CEP5, manipulando um quantidade menor de objetos na triagem coletiva, reduzindo assim, o tempo deste processo.

b) Perspectiva de aquisição de máquinas de leitura do CEP - desde o início de 1997, os Correios adotaram um novo padrão no uso e preenchimento de envelopes, para permitir a adoção da mecanização postal. Já utilizada em São Paulo, Rio de Janeiro e Brasília, a mecanização postal faz com que a separação das correspondências seja realizada por máquinas e não mais de forma manual. Com isto, o carteiro receberá sua correspondência já separada, não participando mais do processo de triagem, dedicando seu tempo ao trabalho de ordenação e entrega dos objetos, proporcionando rapidez e eficiência ao serviço.

\section{Definição do Problema}

$\mathrm{O}$ Correios enfrentam a falta de carteiros para efetuar a entrega dos objetos, bem como o aumento de volume dos mesmos. A grande preocupação está em diminuir o tempo de triagem, ou seja, da separação dos objetos, tempo este que poderia ser utilizado na entrega; e também na otimização do trajeto realizado pelo carteiro, que facilitaria seu trabalho. Desta forma ele poderia entregar uma quantidade maior de objetos, percorrendo o mínimo necessário de trechos que não possuem entrega. Percebe-se que o principal problema é o da divisão inicial do CDD, que é feita atualmente de forma manual, não prevendo a distribuição da carga de forma equilibrada entre os carteiros, tornando-se uma divisão ineficiente. $\mathrm{O}$ problema a ser tratado pode, então, ser dividido em duas fases:

a) Divisão do CDD-Capão da Imbuia em novos DP's (Fase I - formação de clusters), determinando-se qual carteiro deverá atender a quais pontos de entrega (endereço dos usuários). Numa primeira proposta considera-se a 
divisão existente dos códigos de endereçamento postal para realizar tal divisão, com o propósito de facilitar o processo de triagem e de reduzir o tempo dispendido com o mesmo. A segunda proposta não considera tais divisões. Nesta fase foram consideradas as demandas dos pontos de entrega.

b) Roteamento de cada um dos DP's (Fase II roteamento), formando, assim, a seqüência de pontos de parada no trajeto, estabelecendo roteiros que utilizem o mínimo possível de trechos improdutivos. Foram consideradas, nesta fase, as distâncias reais entre os pontos de parada.

Da maneira como o problema foi estabelecido, ele pode ser tratado como um Problema de Roteamento de veículos, podendo ser formulado como um problema de otimização em redes.

\subsection{Dados do Problema}

O CDD-Capão da Imbuia é responsável pela entrega dos objetos nos bairros: Atuba, Bairro Alto, Tarumã, Capão da Imbuia e Cajuru da cidade de Curitiba. A rede viária formada pela região do $\mathrm{CDD}$ compõe o grafo $\mathrm{G}(\mathrm{N}, \mathrm{A}, \mathrm{C})$ do problema, onde $\mathrm{N}$ é o conjunto de nós (pontos de interseção das ruas), A define o conjunto de arcos (trechos de ruas) e C é a matriz de custos (distâncias) entre todos os nós do grafo $\mathrm{G}$, ilustrado na Figura 1a. Os Correios possuem o levantamento da quantidade de objetos entregues por trecho somente da região inferior do CDD, formada pelo bairro do Cajuru. Os dados utilizados neste trabalho são desta região, sobre a qual é proposta, então, a solução do problema, formando o subgrafo $\mathrm{G}_{0}\left(\mathrm{~N}_{0}, \mathrm{~A}_{0}, \mathrm{C}_{0}\right)$ de $\mathrm{G}(\mathrm{N}, \mathrm{A}, \mathrm{C})$, apresentado na Figura 1b.

Em cada trecho de rua (arco do grafo $\mathrm{G}_{0}$ ) existem vários pontos de entrega dos objetos, estabelecidos pelos endereços dos usuários dos serviços postais. Os carteiros atualmente não compartilham entregas num mesmo trecho; assim todos os pontos de um mesmo trecho são associados a um único ponto, que é estabelecido pelo ponto médio do arco. Estes pontos médios formam então o conjunto dos pontos de parada do problema. Designar um ponto de parada a um carteiro é o correspondente a designar um trecho produtivo do grafo $\mathrm{G}_{0}$ a ele, e desta forma estão definidos os seus pontos de entrega, ou seja, os endereços dos usuários.

Tem-se, assim, um novo grafo $\mathrm{G}_{1}$ ilustrado na Figura 2a que é obtido da seguinte forma: se o trecho for produtivo, então é introduzido no grafo $\mathrm{G}_{0}$ o ponto médio do arco, e atribuído a ele a demanda do trecho; caso contrário, o ponto médio não é incluído no grafo. Esta é uma das abordagens de solução para a Fase I do problema - denominada de abordagem trecho.

Além da designação dos pontos de parada formados pelos pontos médios dos trechos produtivos, é proposta também a designação dos pontos de parada correspondentes aos pontos médios das ruas - abordagem rua, ilustrada na Figura $2 \mathrm{~b}$. O objetivo desta segunda abordagem é facilitar ainda mais o processo de triagem realizado pelos carteiros, que precisam memorizar todos os CEP's e nomes das ruas de seus colegas para poder efetuar a separação dos objetos; e facilitar também o processo de entrega, pois como o DP será formado por ruas inteiras (com os mesmos CEP's de oito dígitos) então o carteiro conhecerá as particularidades de cada rua, sabendo com certeza onde deve fazer cada entrega. A obtenção do grafo $\mathrm{G}_{2}$ é análoga a do grafo $G_{1}$, ou seja, ele é formado a partir do grafo $\mathrm{G}_{0}$ com a inclusão de pontos de parada, que neste caso são os pontos médios das ruas. Cada um destes pontos médios são obtidos da seguinte forma: identificam-se os pontos inicial e final da rua (identificada pelo mesmo CEP de oito dígitos), a seguir estes pontos são ligados por um segmento de reta, assim, o ponto médio da rua torna-se o ponto médio do segmento de reta. É atribuído a este ponto a demanda igual a soma das cargas de entrega dos trechos produtivos desta rua.

A abordagem trecho possui o total de 1214 pontos de parada associados aos trechos produtivos do grafo $G_{1}$, que possui no total 1471 trechos, enquanto que na abordagem rua existem 

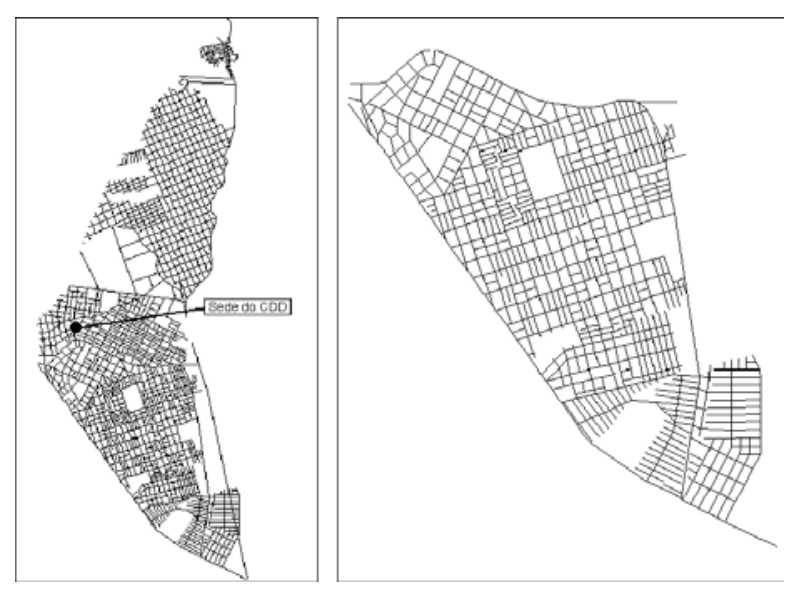

Figura 1 - a) Grafo $G$ associado à rede viária do CDD-Capão da Imbuia b) $\mathbf{G r a f o}_{\mathbf{0}}$ associado à rede viária do bairro do Cajuru

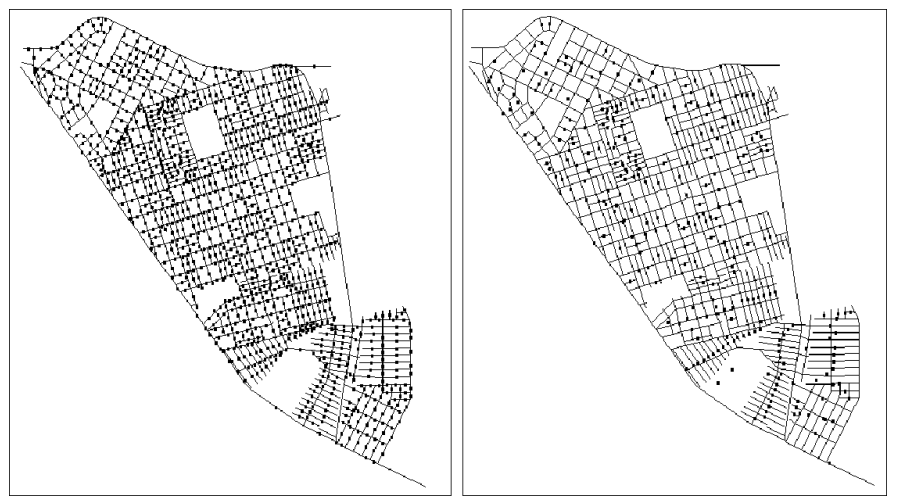

Figura 2 - a) Formação do grafo $G_{1}$ a partir da inclusão dos pontos de parada no grafo $G_{0}$ b) Formação do grafo $G_{2}$ a partir da inclusão dos pontos de parada no grafo $G_{0}$

296 pontos de parada associados às ruas produtivas do grafo $\mathrm{G}_{2}$, dentre suas 330 ruas (em relação aos mesmos CEP's de oito dígitos).

Os Correios possuem o levantamento da carga de entrega dos objetos em todos os trechos da região inferior do CDD. Este valor é que deveria ser considerado como demanda do trecho e, como consequiência, seria a demanda do ponto de parada associado. Porém, existem trechos longos com pouca entrega, outros trechos curtos que possuem muitas entregas, bem como existem aqueles que são curtos ou longos que possuem pouca ou muita entrega. Assim, para haver um equilíbrio na divisão do CDD em DP's, ou seja, para que um carteiro não caminhe mais do que o outro, ou carregue uma quantidade maior de objetos, deve ocorrer uma divisão justa da região. Para isso, os Correios estabeleceram o conceito de valor do trecho em carteiro (VTC). Este valor é um coeficiente estabelecido para cada trecho, que relaciona: velocidade de percorrida, tempo de percorrida, modo de percorrida, tipo de região e carga de entrega. As demandas de cada distrito postal atualmente variam entre 0.68 e 1.25 VTC.

Foi então estabelecida a demanda do ponto de parada da seguinte forma: se a abordagem é trecho, basta associar ao ponto de parada o VTC do trecho como sendo a demanda do trecho, e se a abordagem é rua, então é associado ao ponto 

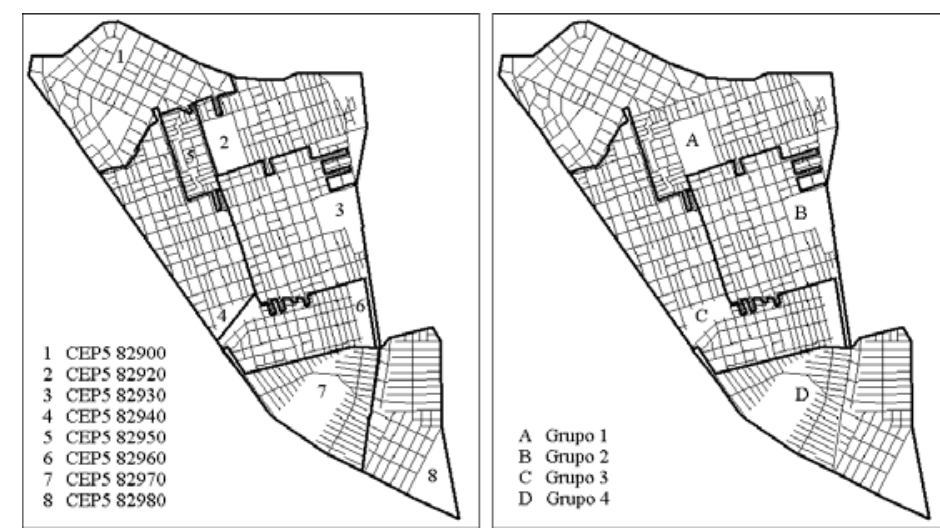

Figura 3 - a) Subdivisão da região inferior do CDD-Capão da Imbuia de acordo com o CEP5 b) Divisão da região inferior do CDD em 4 grupos de CEP5

de parada da rua a soma de todos os VTC dos trechos como sendo a demanda da rua. A demanda total da região é de 13.14 unidades em VTC. Para simplificação, VTC será chamado apenas de demanda do ponto de parada. $\mathrm{O}$ atendimento da região considerada é realizada por 13 carteiros, então a demanda total para cada deve ser aproximadamente uma unidade de VTC.

Cada rua do CDD possui um CEP que é composto de oito dígitos, sendo que os cinco primeiros identificam uma região do $\mathrm{CDD}$ ao qual eles pertencem e os três últimos representam as divisões da rua em pedaços menores, variando conforme seu tamanho e características. Agrupando as ruas que possuem em comum o mesmo CEP5 (os cinco primeiros dígitos do CEP) são formadas oito regiões que dividem a região inferior do CDD, ilustradas na Figura 3a.

\section{Resolução do Problema}

A maioria dos Problemas de Roteamento é NP-Hard. Assim, abordagens conhecidas para resolver perfeitamente este problema crescem exponencialmente em relação ao tempo computacional, de acordo com o tamanho do mesmo. Um recurso freqüente é utilizar heurísticas ou procedimentos aproximados para obter soluções quase-ótimas ao invés de soluções ótimas. No caso do problema estudado é utilizada uma abordagem de resolução por meio de técnicas heurísticas clássicas de roteamento de veículos. A seguir, são mostradas as etapas de resolução e os algoritmos utilizados.

\subsection{Resolução da Fase I: Divisão do CDD em Distritos Postais}

Pela designação de todos os pontos de parada, estabelecidos pela abordagem trecho ou rua aos carteiros, é determinada a divisão do CDD em DP's, onde cada distrito postal deve possuir, em média, a mesma demanda (uma unidade de VTC). Para esta divisão são fornecidas duas propostas: a divisão da região considerando a divisão já existente dos CEP's (proposta 1) e outra sem considerar tal divisão (proposta 2).

\subsubsection{Proposta 1: Divisão do CDD dentro de Grupos de CEP5}

A primeira proposta de divisão do CDD em DP's utiliza agrupamentos de CEP5. Um grupo de CEP5 é formado por um ou mais conjuntos de CEP de cinco dígitos (Figura 3b). Estes agrupamentos são formados de modo que sejam subregiões vizinhas (adjacentes) e que a soma das demandas em VTC de cada sub-região seja aproximadamente um número inteiro. Esta escolha foi obtida manualmente levando em consideração a forma da região. A divisão do CDD, portanto, é obtida de forma que o carteiro 
Quadro 1 - Definição dos grupos de CEP5 (AR - Abordagem Rua, AT - Abordagem Trecho)

\begin{tabular}{|c|c|c|c|c|c|}
\hline $\begin{array}{c}\text { Grupos } \\
(\mathbf{G})\end{array}$ & CEP5 associado & $\begin{array}{c}\text { Demanda do } \\
\text { Grupo }\left(\mathbf{D}_{\mathbf{G}}\right)\end{array}$ & $\begin{array}{c}\text { Quantidade de } \\
\text { Carteiros no } \\
\text { Grupo }\left(\mathbf{M}_{\mathbf{G}}\right)\end{array}$ & $\begin{array}{c}\text { Demanda Média } \\
\left(\mathbf{D}_{\mathbf{G}} / \mathbf{M}_{\mathbf{G}}\right)\end{array}$ & $\begin{array}{c}\text { Quantidade de } \\
\text { Pontos de Parada } \\
(\mathbf{A R} / \mathbf{A T})\end{array}$ \\
\hline 1 & $82900,82920,82950$ & 4.219716 & 4 & 1.054929 & $119 / 419$ \\
\hline 2 & 82930 & 2.022772 & 2 & 1.011386 & $42 / 208$ \\
\hline 3 & 82940,82960 & 4.006407 & 4 & 1.001601 & $67 / 367$ \\
\hline 4 & 82970,82980 & 2.899339 & 3 & 0.966446 & $68 / 220$ \\
\hline
\end{tabular}

Quadro 2 - Definição do único grupo de CEP5 para a proposta 2 (AR - Abordagem Rua, AT - Abordagem Trecho)

\begin{tabular}{|c|c|c|c|c|c|}
\hline $\begin{array}{c}\text { Grupo } \\
(\mathbf{G})\end{array}$ & CEP5 associado & $\begin{array}{c}\text { Demanda do } \\
\text { Grupo }\left(\mathbf{D}_{\mathbf{G}}\right)\end{array}$ & $\begin{array}{c}\text { Quantidade de } \\
\text { Carteiros no } \\
\mathbf{G r u p o}^{\left(\mathbf{M}_{\mathbf{G}}\right)}\end{array}$ & $\begin{array}{c}\text { Demanda média } \\
\left(\mathbf{D}_{\mathbf{G}} / \mathbf{M}_{\mathbf{G}}\right)\end{array}$ & $\begin{array}{c}\text { Quantidade de } \\
\text { Pontos de Parada } \\
(\mathbf{A R} / \mathbf{A T})\end{array}$ \\
\hline único & os 8 conjuntos & 13.148234 & 13 & 1.011402 & $296 / 1214$ \\
\hline
\end{tabular}

possua seu DP contido em um, até o máximo de 3 grupos de sub-regiões formadas pelo CEP5. Com isto, as correspondências já seriam separadas de acordo com o seu CEP5 pelo CT, fazendo com que os carteiros manipulassem uma quantidade menor de objetos, apenas aqueles pertencentes ao seu grupo de CEP5. Esta proposta fornece então uma solução imediata para o problema atual de triagem coletiva, simplificando-o, significativamente, conforme exposto no Quadro 1.

\subsubsection{Proposta 2: Divisão de Todo o CDD}

Com a perspectiva de aquisição de máquinas para identificação dos endereços de entrega dos objetos (ou dos CEP's) que são capazes de separar as correspondências de acordo com o DP correspondente, não há mais necessidade de preocupar-se em facilitar o processo de triagem manual, pois este seria eliminado. Assim, podese efetuar a divisão de todo CDD em 13 DP's de uma única vez, considerando a região toda, realizando desta forma uma divisão equânime entre os carteiros. A proposta 2, então, efetua a divisão da região inferior do CDD de uma única vez, designando os pontos de parada, dentro da abordagem trecho ou rua, dentre os seus 13 carteiros, sendo que cada um terá uma demanda média de 1.011402 (em VTC) de carga de trabalho.

Esta proposta pode ser estabelecida de forma análoga à proposta 1 , sendo que existe agora apenas 1 único grupo de CEP5 formado por todos os conjuntos de CEP5. Esta situação pode ser analisada no Quadro 2.

\subsubsection{Aplicação dos Algoritmos de Rotea- mento de Veículos para Obter a Divisão do CDD em DP's}

Nas duas propostas apresentadas nas seções 4.1.1 e 4.1.2 foram aplicados os algoritmos heurísticos de roteamento de vários veículos com vários depósitos. As rotas obtidas determinam os distritos postais dos carteiros. Os pontos de parada a serem visitados pelos carteiros correspondem aos pontos médios de cada rua ou trecho de rua que possuem entrega.

A demanda média de cada grupo considerado (cada um dos 4 grupos segundo a proposta $1 \mathrm{ou}$ o grupo único formado pela região toda segundo a proposta 2 - quadros 1 e 2) é fornecida dividindo-se a demanda total do grupo pela 

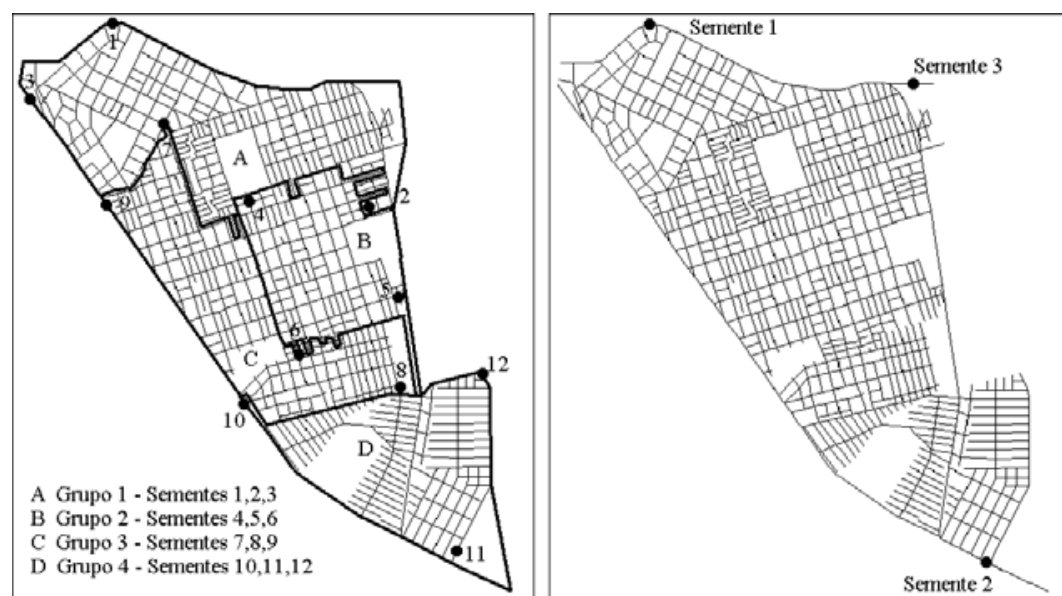

Figura 4 - a) Posição das sementes (depósitos fictícios) para a proposta 1 b) Posição das sementes para a proposta 2

quantidade de carteiros do grupo. O estabelecimento da carga máxima de um carteiro (demanda máxima que ele pode atender) é fornecida multiplicando-se a demanda média do grupo por uma fator $\alpha$ de aumento. Foram realizados testes variando-se $\alpha$ entre 1,03 e 1,10. Este fator tem o objetivo de fornecer uma margem de folga para a carga máxima que o carteiro pode transportar. Se considerássemos que esta carga fosse exatamente a mesma para cada carteiro, o algoritmo utilizado para a formação de clusters que considera a demanda deixaria vários pontos de parada sem designação, havendo a necessidade de serem feitos muitos ajustes posteriores.

Considerando a sede do CDD como o depósito fictício para a formação dos clusters, teríamos DP's com formas alongadas. Para evitar isto, foram criados depósitos fictícios situados dentro da região e com suas posições coincidindo com algum ponto de parada. Para determinar a localização destes depósitos fictícios utilizou-se o algoritmo de geração de sementes (PARAÍBA, 1990). Este algoritmo escolhe a primeira semente como sendo o ponto de parada mais próximo da sede do CDD. Em seguida, escolhe a próxima semente como sendo o ponto de parada tal que a soma das distâncias dele a todas as outras sementes já obtidas seja máxima. O processo é repetido até que todas as sementes desejadas sejam obtidas. Foram testadas várias quantidades de sementes de acordo com a proposta de resolução, sendo que uma das situações para cada proposta está ilustrada na Figura 4.

Definidas as localizações dos depósitos, a demanda dos pontos de parada e a carga máxima de cada carteiro, pode-se utilizar os algoritmos de roteamento de vários veículos e vários depósitos para a obtenção dos clusters. O procedimento descrito a seguir foi generalizado, sem fazer distinção entre os tipos de propostas (1 e 2) e de abordagens (trecho e rua).

Inicialmente é aplicado o chamado algoritmo M-Dep das razões (GOLDEN et al., 1977) para formação temporária dos agrupamentos de pontos de parada (cada grupo é considerado separadamente - quadros 1 e 2) em torno das sementes (depósitos), sem considerar a demanda e utilizando a distância euclidiana (esta designação é temporária). Este algoritmo obtém uma lista de valores (razões), e por meio dela é designado o ponto de parada a um dos depósitos. Para cada ponto de parada (nó i) são determinados os dois depósitos mais próximos segundo a distância euclidiana, $t_{i}^{\prime}$ e $t_{i}^{\prime \prime}$; a seguir são calculadas as razões destas distâncias $\left(\mathrm{r}_{\mathrm{i}}=\mathrm{c}_{\mathrm{it}_{\mathrm{i}}} / \mathrm{c}_{\mathrm{iti}_{\mathrm{i}}^{\prime \prime}}\right)$. Os nós são ordenados de acordo com os valores das razões em ordem crescente. Esta lista determina a ordem na qual os nós serão designados aos depósitos: aqueles que estão relativamente 
próximos ao primeiro depósito e mais afastados em relação ao segundo são considerados primeiro. Os nós i que possuem a razão $r_{i}<\delta$ $(0<\delta<1)$ são designados ao depósito mais próximo $\mathrm{t}_{\mathrm{i}}^{\prime}$. A cada inclusão de um novo nó numa rota é utilizado o algoritmo de inserção econômica para determinar a sua posição dentro da rota (GOLDEN et al., 1980; BODIN et al., 1983). Os nós i que possuem a razão $r_{i} \geq \delta$ são designados a um dos outros depósitos existentes da seguinte forma: para cada dois nós adjacentes j e k, que já estão designados a um depósito t, calcular o custo (distância euclidiana) $\mathrm{c}_{\mathrm{ji}}+\mathrm{c}_{\mathrm{ik}}-\mathrm{c}_{\mathrm{jk}}$ de inserção do nó i entre os nós j e k. O nó i deve ser designado ao depósito $t$ associado ao par $(\mathrm{j}, \mathrm{k})$ que forneceu o menor custo (algoritmo de inserção econômica). Neste problema utilizou-se $\delta=0,8$.

A seguir, é aplicado o algoritmo dos savings com múltiplos depósitos - denominado M-DepCW (TILLMAN et al., 1972), o qual é uma generalização do algoritmo dos savings de Clarke e Wright (CLARKE \& WRIGHT, 1964), que passa a considerar a demanda de cada ponto de parada para a formação dos clusters. O algoritmo M-DepCW necessita da designação temporária dos pontos a algum depósito, já obtida pelo algoritmo M-Dep das razões. Formam-se então $\mathrm{n}$ rotas iniciais, temporárias, uma para cada nó, ligadas ao depósito correspondente. Para cada par de nós i e j, e cada depósito $\mathrm{k}$, são calculados os savings $\mathrm{s}_{\mathrm{ij}}{ }^{\mathrm{k}} \mathrm{em}$ função dos custos $\mathrm{c}$ (distância euclidiana): $\mathrm{s}_{\mathrm{ij}}{ }^{\mathrm{k}}=\overline{\mathrm{c}}_{\mathrm{i}}{ }^{\mathrm{k}}+\overline{\mathrm{c}}_{\mathrm{j}}{ }^{\mathrm{k}}-\mathrm{c}_{\mathrm{ij}}$, onde: $\overline{\mathrm{c}}_{\mathrm{i}}{ }^{\mathrm{k}}=2 \min _{\mathrm{t} \in \mathrm{Conj} \text { Dep }}\left\{\mathrm{c}_{\mathrm{i}}{ }^{\mathrm{t}}\right\}-\mathrm{c}_{\mathrm{i}}{ }^{\mathrm{k}}$, se o nó i ainda não teve uma designação permanente, ou $\overline{\mathrm{c}}_{\mathrm{i}}{ }^{\mathrm{k}}=\mathrm{c}_{\mathrm{i}}{ }^{\mathrm{k}}$, caso contrário. $\mathrm{O}$ saving representa a economia na distância total viajada quando se liga i e j a $\mathrm{k}$. Estes valores são ordenados numa lista de maneira decrescente. $\mathrm{O}$ método liga sucessivamente pares de nós com o objetivo de reduzir o custo total, mas a partir do momento em que dois ou mais nós foram designados a uma rota comum a partir de um depósito, eles não podem ser redesignados a um outro depósito. E ainda, como no algoritmo original dos savings de Clarke e Wright, os nós i e j podem ser ligados se e somente se i e $\mathrm{j}$ não são pontos interiores da rota. A cada passo, a escolha de ligar um par de nós i e j de uma rota a partir de um depósito $\mathrm{k}$ é feita em termos dos savings quando são ligados i e $\mathrm{j}$ a $\mathrm{k}$. Os nós $\mathrm{i}$ e $\mathrm{j}$ são ligados ao depósito $\mathrm{k}$ tal que $\mathrm{s}_{\mathrm{ij}}{ }^{\mathrm{k}}$ seja máximo, e que forneça uma solução factível em relação ao controle de capacidade da rota (no caso é a carga máxima que o carteiro pode transportar). Os valores dos savings para estes pontos i e j são atualizados, pois tornaram-se nós com designação permanente. Este procedimento é então repetido até o término da lista de valores de savings. A quantidade de rotas utilizada é dada pelo valor de $\mathrm{M}_{\mathrm{G}}$ (quantidade de carteiros que atende ao grupo de CEP5 considerado).

Como os valores dos savings podem ser negativos, ou ainda, pelo fato do saving indicar a designação de um ponto, a rota que já se encontra com a capacidade máxima utilizada, tem-se que ao final do processo ficam pontos de parada sem designação. Foi realizado então um ajuste das respostas incluindo os pontos de paradas sem designação nas rotas obtidas pelo algoritmo M-DepCW. Foi feita a seguinte operação: para cada nó i que não está roteirizado é determinada a posição de inserção, que é obtida por determinar o nó j, de alguma das $\mathrm{M}$ rotas já obtidas, tal que $c_{i j}$ seja mínimo e que não ultrapasse o limite da capacidade da rota. Este é o processo de inserção utilizado pelo algoritmo de inserção mais próxima (GOLDEN et al., 1980).

Foram obtidos, a seguir, novos pontos iniciais e finais para cada rota. Eles foram obtidos como sendo os pontos mais próximos de todos os outros pontos, ou seja, foi calculada a distância acumulada de cada ponto de parada até os outros pontos da mesma rota, e escolhido como ponto inicial da rota aquele que forneceu a menor das somas das distâncias, e como ponto final o que forneceu a segunda menor soma das distâncias. A intenção é que o processo de melhoria entre rotas (explicado a seguir) troque os pontos que estejam no meio da rota, ou seja, os que estejam mais afastados da concentração dos pontos de parada. Precisou-se, então, fornecer uma nova 
seqüência para cada rota, e para isso utilizou-se o algoritmo de inserção econômica (GOLDEN et al., 1980; BODIN et al., 1983). Este algoritmo pode ser aplicado também para solucionar um problema de roteamento de vários veículos e um depósito. No caso, ele foi aplicado ao roteamento de apenas um veículo (carteiro). O primeiro passo é identificar o nó mais afastado do ponto inicial da rota. A seguir, deve-se obter a rota inicial formada pelos: ponto inicial, ponto mais afastado do ponto inicial da rota e pelo ponto final. Para cada nó i não roteirizado, calcular a posição mais econômica para sua inserção na rota da seguinte forma: determinar dois nós adjacentes $\mathrm{j}$ e $\mathrm{k}$ da rota, tal que $\mathrm{c}_{\mathrm{ji}}+\mathrm{c}_{\mathrm{ik}}-\mathrm{c}_{\mathrm{jk}}$ seja mínimo. Inserir o nó cujo valor de inserção seja mínimo na rota. Recalcular as posições de inserção econômica para cada nó i não roteirizado, continuar o processo até que todos os nós estejam roteirizados.

A última etapa para a formação dos clusters é a utilização dos algoritmos de melhoria de rotas. Eles fazem trocas de posições dos nós entre as rotas ou dentro de uma mesma rota se esta nova configuração resultar num custo (comprimento da rota) menor do que o anterior.

Foram utilizados inicialmente os algoritmos de troca simples e dupla entre rotas (WATERS, 1987). O algoritmo de troca simples funciona da seguinte forma: para cada nó i da rota I são determinados nós $\mathrm{j}$ ' e $\mathrm{j}$ " de uma rota $\mathrm{J}$ tal que $\left[\mathrm{c}\left(\mathrm{i}^{\prime}, \mathrm{i}\right)+\mathrm{c}\left(\mathrm{i}, \mathrm{i}^{\prime \prime}\right)+\mathrm{c}\left(\mathrm{j}^{\prime}, \mathrm{j}^{\prime \prime}\right)-\left[\mathrm{c}\left(\mathrm{i}^{\prime}, \mathrm{i}^{\prime \prime}\right)+\mathrm{c}\left(\mathrm{j}^{\prime}, \mathrm{i}\right)+\right.\right.$ $c(i, j ")]>0$ ] (onde i' e i" são os nós adjacentes ao nó i) seja máximo e que a demanda do nó i possa ser atendida pela rota J. É efetuada a inserção do nó i na rota $\mathrm{J}$ de acordo com o maior valor obtido. Continuar este procedimento para cada rota considerada até que nenhuma melhoria a mais seja obtida. O procedimento de troca dupla de nós é semelhante ao anterior: são considerados agora dois pontos $\mathrm{i}$, da rota $\mathrm{I}$, e $\mathrm{j}$, da rota J, e calculado o valor: $\left[\mathrm{c}\left(\mathrm{i}^{\prime}, \mathrm{i}\right)+\mathrm{c}\left(\mathrm{i}, \mathrm{i}^{\prime \prime}\right)+\mathrm{c}\left(\mathrm{j}^{\prime}, \mathrm{j}\right)+\right.$ $\left.c\left(j, j^{\prime \prime}\right)-\left[c\left(i^{\prime}, j\right)+c\left(j, i^{\prime \prime}\right)+c\left(j^{\prime}, i\right)+c\left(i, j{ }^{\prime}\right)\right]>0\right]$ (i' e i” adjacentes ao nó $i$, e j' e j'adjacentes ao $j$ ) para cada par de nós i e j. O maior valor indica quais pontos devem ser trocados entre as rotas, desde que não ultrapasse a capacidade de cada rota. Este procedimento é repetido até que nenhuma melhoria mais seja obtida.

Para melhorias das rotas foi utilizado o algoritmo k-opt (LIN et al., 1973), utilizando k igual a 2 e 3. Para cada rota são desconectados $\mathrm{k}$ arcos (por exemplo, para $\mathrm{k}=2$ são desconectados 2 arcos que unem 4 nós, podendo ou não serem adjacentes). Estes $\mathrm{k}$ caminhos são reconectados formando uma nova rota. Se o comprimento da nova rota for menor do que o original, então esta nova configuração é utilizada. Escolhe-se novos $\mathrm{k}$ arcos e continua-se o procedimento até que nenhuma melhoria mais seja obtida.

Após a utilização dos procedimentos de melhorias das rotas tem-se os clusters definitivos de pontos, obtendo-se os distritos postais de cada um dos carteiros. A seguir deve ser realizado o roteamento de cada distrito, considerando agora as distâncias reais.

\subsection{Resolução da Fase II: Roteamento das Sub-regiões}

Após a divisão do CDD em DP's há a necessidade de efetuar o roteamento dos mesmos. Para tanto, é proposto o uso de quatro algoritmos de roteamento de veículos, três deles referentes ao roteamento de nós e um de roteamento de arcos.

\subsubsection{Aplicação dos Algoritmos de Rotea- mento de Nós}

Os algoritmos de roteamento de nós adotados neste trabalho são: inserção econômica (GOLDEN et al., 1980), savings de Clarke e Wright (CLARKE \& WRIGHT, 1964) e sweep (GILLETT et al., 1974). Estes algoritmos fornecem soluções para o problema de roteamento de um ou vários veículos em relação a um depósito. Nesta etapa eles foram aplicados a cada rota separadamente.

O algoritmo de inserção econômica já foi apresentado no item 4.1.3. O algoritmo dos 
savings de Clarke e Wright funciona da seguinte maneira: inicialmente é obtida uma solução inicial consistindo em servir cada nó exclusivamente por uma rota, ligada ao depósito (nó 0). São calculados os savings para cada par de nós i e j: $s_{i j}=c_{0 i}+c_{0 j}-c_{i j}$ (o custo $c_{i j}$ é dado pela distância real entre $\mathrm{i}$ e j). Estes valores são colocados em ordem decrescente. Os nós i e $\mathrm{j}$ são unidos de acordo com esta seqüência dada pelos savings.

$\mathrm{O}$ algoritmo sweep fornece a seqüência dos nós da seguinte maneira: inicialmente é realizada uma mudança de coordenadas tal que o depósito coincida com a nova origem do sistema. São obtidas as coordenadas polares para cada nó i: ângulo e raio. É formada uma lista dos nós, ordenados pelos ângulos em ordem crescente. A rota é formada, começando-se pelo primeiro nó da lista e incluindo-se os demais, seguindo a sequiência da lista.

Se a abordagem da Fase I foi considerar a rua toda para formação do distrito, então nesta nova fase, cada uma delas foi subdividida em trechos, e foram utilizados para roteamento apenas os trechos produtivos dessa rua. Assim, os pontos de parada do DP são os pontos médios dos trechos produtivos do referido DP, tanto da abordagem trecho quanto rua.

Para os algoritmos de roteamento de nós, o roteamento de cada DP foi realizado da seguinte forma: (1) obtenção dos pontos de parada do DP; (2) definição das coordenadas x e y máximas e mínimas dos pontos de parada: xmax, ymax, xmin e ymin, para formação de um retângulo com vértices (xmin-100,ymin-100), (xmin-100, $y \max +100),(x \operatorname{xax}+100, y \min -100)$ e $(x \max +100$, ymax+100), unidade em metros; (3) formação do grafo $\mathrm{G}_{3}$ composto de todos os pontos de parada do DP e dos vértices do grafo inicial $\mathrm{G}_{0}$ que estão contidos dentro do retângulo definido no passo 2 anterior; (4) cálculo da distância real entre os nós do grafo $\mathrm{G}_{3}$, aplicando o algoritmo de Floyd (FLOYD, 1962); (5) aplicação de um dos algoritmos de roteamento de nós sobre os pontos de parada, sendo que os pontos inicial e final sempre são os mais próximos da sede do
CDD (para que os algoritmos possam ser comparados); (6) utilização do algoritmo de melhoria de rota 2-opt (o algoritmo 3-opt não foi utilizado pela grande quantidade de pontos de parada), aplicado sobre a sequiência da rota dada pelo passo 5 anterior, fornecendo a sequiência dos pontos de parada para a rota; (7) recuperação da trajetória da rota, quadra a quadra, entre os pontos de parada, fornecendo a sequiência do trajeto para o DP.

\subsubsection{Aplicação do Algoritmo de Roteamento de Arcos}

$\mathrm{O}$ algoritmo utilizado para o roteamento de arcos é o algoritmo do carteiro chinês (BODIN et al., 1983). Inicialmente deve ser obtida a matriz de custos das arestas do grafo considerado. Identificar os vértices de grau ímpar. Se não existirem vértices de grau ímpar então realizar o passo final do procedimento, pois existe um circuito euleriano no grafo. Caso contrário, obter o mínimo custo entre todos os vértices de grau ímpar. Determinar o matching de mínimo custo (combinação dos vértices dois a dois). Introduzir as arestas de custo mínimo no grafo. Passo final: formar o circuito euleriano, utilizando a Regra de Fleury (CHRISTOFIDES, 1975).

O algoritmo do carteiro chinês é aplicado a um grafo conexo, ou seja, a região deve possuir ligações entre todos os seus arcos, formando uma região não disjunta. Porém, os DP's estabelecidos na Fase I possuem arcos ou grupos de $\operatorname{arcos}$ (subgrafos conexos) que não são ligados a região toda do DP, estabelecendo um grafo desconexo. Portanto, existe a necessidade preliminar à aplicação do algoritmo do carteiro chinês, de interligar a região do DP, pela inclusão de arcos, para deixar o grafo relativo ao DP conexo. Após esta etapa, procede-se com a utilização do algoritmo do carteiro chinês.

Se a abordagem da Fase I foi rua, então cada rua foi subdividida em trechos, e foram utilizados para roteamento apenas os trechos produtivos. Assim, os pontos de parada do DP, que são os pontos médios dos trechos produtivos 
do referido DP, definem os arcos produtivos que devem ser atravessados pelo carteiro, tanto da abordagem trecho quanto rua.

$O$ roteamento de cada DP foi realizada da seguinte forma: (1) formação do grafo $G_{4}$ composto de todos os trechos produtivos do DP, que foram definidos pela designação dos seus pontos médios na Fase I, sendo seus vértices as extremidades de cada arco (trecho produtivo) do DP; (2) identificação das regiões disjuntas, ou seja, aquelas que não possuem ligações por meio de arcos existentes do grafo $\mathrm{G}_{4}$, utilizando para isso o algoritmo de Floyd; (3) unir duas a duas as regiões disjuntas por arcos do grafo inicial $\mathrm{G}_{0}$, formando o grafo conexo $\mathrm{G}_{5}$; (4) cálculo da distância real entre os vértices do grafo $\mathrm{G}_{5}$, aplicando o algoritmo de Floyd; (5) aplicação do algoritmo do carteiro chinês sobre os arcos do grafo $\mathrm{G}_{5}$, sendo que o arco inicial da rota é aquele que possui uma das extremidades mais próximas da sede do CDD, obtendo-se assim, a sequiência de percorrida dos arcos; (6) recuperação da trajetória da rota quadra a quadra, fornecendo a seqüência de percorrida dos arcos, determinando o trajeto para o DP.

\section{Resultados Numéricos}

A divisão atual da região inferior abrangida pelo CDD-Capão da Imbuia, conforme já analisado, necessita de 13 carteiros para a tarefa de entrega dos objetos. São então fornecidas a seguir as respostas obtidas pelos algoritmos anteriormente apresentados.

\subsection{Respostas para a Fase I - Divisão do CDD em DP's}

Foram realizados ao todo 4 conjuntos de testes, alternando-se entre dividir a região toda do CDD, considerando ou não a divisão existente dos grupos de CEP's, e entre as abordagens rua e trecho, formando um total de 31 testes. Nas soluções apresentadas a seguir, são fornecidas informações sobre cada um dos testes realizados, o fator de aumento $\alpha$ utilizado, a quantidade de sementes utilizada para cada grupo de CEP5, a carga máxima utilizada $(\alpha$. D $=$ fator de aumento . demanda total da região), distância total entre os pontos de parada após a utilização do algoritmo M-DepCW e do ajuste (inserção mais próxima), distância total após o algoritmo de inserção econômica e distância total após a utilização dos algoritmos de melhorias de rotas. As distâncias são euclidianas e fornecidas em metros.

Para a abordagem trecho não foi utilizado o algoritmo 3-opt para melhoria da seqüência entre os pontos de parada devido a grande quantidade de nós de cada uma das rotas.

Para a proposta 1, considerando a divisão de CEP's, abordagem rua, foram realizados 10 testes, variando-se os parâmetros de fator de aumento $\alpha$ e quantidade de sementes utilizadas por grupos de CEP5. Os melhores resultados são dados pelos testes de números 3 e 4 , os quais forneceram DP's mais concentrados e distância total menor (euclidiana) entre os pontos de parada, conforme exposto no Quadro 3. Este foi o critério para a escolha das melhores soluções.

Para a proposta 1, considerando a divisão de CEP's, abordagem trecho, foram realizados 8 testes, apresentados no Quadro 4, variando-se os parâmetros de fator de aumento $\alpha$ e quantidade de sementes utilizadas por grupos de CEP5. Os melhores resultados são dados pelos testes de números 14 e 17.

Já para a proposta 2, que não considera a divisão dos CEP's, abordagem rua, foram realizados 5 testes, apresentados no Quadro 5, variando-se os parâmetros de fator de aumento $\alpha$ e quantidade de sementes utilizadas por grupos de CEP5. Os melhores resultados são dados pelos testes de números 23 e 24 .

$\mathrm{E}$, finalmente para a proposta 2 , que não considera a divisão dos CEP's, abordagem trecho, foram realizados 8 testes, apresentados no Quadro 6, variando-se os parâmetros de fator de aumento $\alpha$ e quantidade de sementes utilizadas por grupos de CEP5. Os melhores resultados são dados pelos testes de números 32 e 37 . Para o teste 33 , formaram-se apenas 12 rotas. 
Quadro 3 - Comparação dos testes realizados para a fase I, proposta 1, abordagem rua

\begin{tabular}{|c|c|c|c|c|c|c|c|c|c|}
\hline \multirow[b]{2}{*}{ Teste } & \multirow{2}{*}{$\begin{array}{c}\text { Fator de } \\
\text { aumento } \\
\alpha\end{array}$} & \multicolumn{4}{|c|}{$\begin{array}{c}\text { Quantidade de sementes para } \\
\text { cada Grupo CEP5 }\end{array}$} & \multirow{2}{*}{$\begin{array}{c}\text { Carga } \\
\text { máxima } \\
\text { Total }(\alpha . D)\end{array}$} & \multirow{2}{*}{$\begin{array}{c}\text { Distância } \\
\text { total } \\
\text { MdepCW e } \\
\text { Ajuste }\end{array}$} & \multirow{2}{*}{$\begin{array}{c}\text { Distância } \\
\text { total } \\
\text { Inserção } \\
\text { Econômica }\end{array}$} & \multirow{2}{*}{$\begin{array}{c}\text { Distância } \\
\text { total } \\
\text { Melhorias }\end{array}$} \\
\hline & & 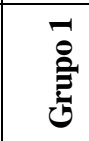 & ڤี & 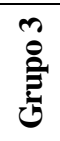 & 竎 & & & & \\
\hline 1 & 1.05 & 3 & 2 & 3 & 2 & 13.8 & 58139.68 & 56845.28 & 49147.37 \\
\hline 2 & 1.05 & 1 & 1 & 1 & 1 & 13.8 & 51340.99 & 51436.29 & 43912.63 \\
\hline 3 & 1.06 & 1 & 1 & 1 & 1 & 13.93 & 50280.34 & 51705.04 & 42839.75 \\
\hline 4 & 1.07 & 1 & 1 & 1 & 1 & 14.06 & 52458.51 & 55645.43 & 43406.98 \\
\hline 5 & 1.03 & 2 & 2 & 2 & 2 & 13.54 & 57941.4 & 58246.48 & 49851.17 \\
\hline 6 & 1.04 & 2 & 2 & 2 & 2 & 13.67 & 59233.46 & 60163.57 & 51424.01 \\
\hline 7 & 1.05 & 2 & 2 & 2 & 2 & 13.8 & 58175.85 & 57421.51 & 47111.21 \\
\hline 8 & 1.06 & 2 & 2 & 2 & 2 & 13.93 & 57504.1 & 57401.05 & 46329.29 \\
\hline 9 & 1.07 & 2 & 2 & 2 & 2 & 14.06 & 57805.11 & 57441.48 & 46804.87 \\
\hline 10 & 1.10 & 2 & 2 & 2 & 2 & 14.46 & 57283.35 & 57963.47 & 44201.35 \\
\hline
\end{tabular}

Quadro 4 - Comparação dos testes realizados para a fase I, proposta 1, abordagem trecho

\begin{tabular}{|c|c|c|c|c|c|c|c|c|c|}
\hline \multirow[b]{2}{*}{ Teste } & \multirow{2}{*}{$\begin{array}{c}\text { Fator de } \\
\text { aumento } \\
\alpha \alpha\end{array}$} & \multicolumn{4}{|c|}{$\begin{array}{l}\text { Quantidade de sementes para } \\
\text { cada Grupo CEP5 }\end{array}$} & \multirow{2}{*}{$\begin{array}{c}\text { Carga } \\
\text { máxima } \\
\text { total }(\alpha . D)\end{array}$} & \multirow{2}{*}{$\begin{array}{c}\text { Distância } \\
\text { total } \\
\text { MdepCW e } \\
\text { Ajuste }\end{array}$} & \multirow{2}{*}{$\begin{array}{c}\text { Distância } \\
\text { total } \\
\text { Inserção }\end{array}$} & \multirow{2}{*}{$\begin{array}{c}\text { Distância } \\
\text { total } \\
\text { Melhorias }\end{array}$} \\
\hline & & 㺼 & है & है & 离 & & & & \\
\hline 11 & 1.05 & 1 & 1 & 1 & 1 & 13.8 & 153911.1 & 123998.7 & 104770.9 \\
\hline 12 & 1.07 & 1 & 1 & 1 & 1 & 14.06 & 157364.29 & 123089.4 & 106466.3 \\
\hline 13 & 1.10 & 1 & 1 & 1 & 1 & 14.46 & 157489.9 & 120616.4 & 106327.4 \\
\hline 14 & 1.05 & 2 & 2 & 2 & 2 & 13.8 & 195065.3 & 118253.2 & 101731.8 \\
\hline 15 & 1.07 & 2 & 2 & 2 & 2 & 14.06 & 194299.9 & 115856.5 & 103346.8 \\
\hline 16 & 1.09 & 2 & 2 & 2 & 2 & 14.33 & 197131.9 & 115283 & 102881.6 \\
\hline 17 & 1.09 & 2 & 2 & 2 & 2 & 14.33 & 181306.7 & 113253.7 & 101146.3 \\
\hline 18 & 1.07 & 2 & 2 & 2 & 2 & 14.06 & 193340.1 & 116561.8 & 104019.8 \\
\hline
\end{tabular}

A proposta 1 que considera os CEP's para a divisão do CDD em DP's e com o uso da abordagem rua, nota-se que o trabalho de triagem das correspondências pode ser facilitado, pois os carteiros poderão manipular uma quantidade bem menor de correspondências; bem como auxilia o processo de entrega dos objetos, pois os DP's dos carteiros serão constituídos por ruas inteiras; assim, ele ficará encarregado pela entrega das correspondências das ruas críticas (por inteiro), podendo memorizar a sequiência da numeração utilizada neste tipo de rua.

$\mathrm{O}$ resultado do teste 3 , proposta 1 - considerando a divisão de CEP's e abordagem rua é mostrado no Quadro 7 a seguir. $O$ fator de aumento $\alpha$ utilizado foi de $1.06 \mathrm{e}$, portanto, a 
Quadro 5 - Comparação dos testes realizados para a fase I, proposta 2, abordagem rua

\begin{tabular}{|c|c|c|c|c|c|c|}
\hline Teste & $\begin{array}{c}\text { Fator de } \\
\text { aumento } \alpha\end{array}$ & $\begin{array}{c}\text { Quantidade de sementes } \\
\text { para todo o CDD (grupo } \\
\text { único de CEP5) }\end{array}$ & $\begin{array}{c}\text { Carga } \\
\text { máxima } \\
\text { total }(\boldsymbol{\alpha} \text { *D) }\end{array}$ & $\begin{array}{c}\text { Dist. total } \\
\text { MDepCW / } / \\
\text { Ajuste }\end{array}$ & $\begin{array}{c}\text { Distância } \\
\text { total } \\
\text { Inserção }\end{array}$ & $\begin{array}{c}\text { Distância } \\
\text { total } \\
\text { Melhorias }\end{array}$ \\
\hline 21 & 1.03 & 2 & 13.54 & 46590.01 & 55168.79 & 44850.75 \\
\hline 22 & 1.04 & 2 & 13.67 & 46552.55 & 54137.25 & 44017.37 \\
\hline $\mathbf{2 3}$ & $\mathbf{1 . 0 5}$ & $\mathbf{2}$ & $\mathbf{1 3 . 8}$ & $\mathbf{4 6 1 3 4 . 2 1}$ & $\mathbf{5 6 4 1 5 . 5 2}$ & $\mathbf{4 2 0 9 5 . 9 1}$ \\
\hline $\mathbf{2 4}$ & $\mathbf{1 . 0 6}$ & $\mathbf{2}$ & $\mathbf{1 3 . 9 3}$ & $\mathbf{4 5 5 5 1 . 2 4}$ & $\mathbf{5 3 1 8 4 . 5 3}$ & $\mathbf{4 3 1 4 4 . 3 8}$ \\
\hline 25 & 1.07 & 2 & 14.06 & 45553.77 & 54908.67 & 44983.52 \\
\hline
\end{tabular}

Quadro 6 - Comparação dos testes realizados para a fase I, proposta 2, abordagem trecho

\begin{tabular}{|c|c|c|c|c|c|c|}
\hline Teste & $\begin{array}{c}\text { Fator de } \\
\text { aumento } \alpha\end{array}$ & $\begin{array}{c}\text { Quantidade de sementes } \\
\text { para todo o CDD (grupo } \\
\text { único de CEP5) }\end{array}$ & $\begin{array}{c}\text { Carga } \\
\text { máxima } \\
\text { total }(\boldsymbol{\alpha} . \mathbf{D})\end{array}$ & $\begin{array}{c}\text { Dist. total } \\
\text { MdepCW e } \\
\text { Ajuste }\end{array}$ & $\begin{array}{c}\text { Distância } \\
\text { total } \\
\text { Inserção }\end{array}$ & $\begin{array}{c}\text { Distância } \\
\text { total } \\
\text { Melhorias }\end{array}$ \\
\hline 31 & 1.07 & 1 & 14.06 & 111082 & 117890.5 & 106598.3 \\
\hline $\mathbf{3 2}$ & $\mathbf{1 . 0 5}$ & $\mathbf{1}$ & $\mathbf{1 3 . 8}$ & $\mathbf{1 1 2 4 4 3 . 9}$ & $\mathbf{1 2 1 0 1 7}$ & $\mathbf{1 0 6 0 5 3 . 2}$ \\
\hline 33 & 1.10 & 1 & 13.35 & 110638.4 & 123617.9 & 105180.2 \\
\hline 34 & 1.05 & 2 & 13.8 & 139324 & 131181.6 & 117769.6 \\
\hline 35 & 1.06 & 2 & 13.93 & 136639.6 & 128724.9 & 105517.9 \\
\hline 36 & 1.07 & 2 & 14.06 & 130910.7 & 123575.1 & 106005.7 \\
\hline $\mathbf{3 7}$ & $\mathbf{1 . 0 8}$ & $\mathbf{2}$ & $\mathbf{1 4 . 2}$ & $\mathbf{1 3 6 2 7 9 . 7 9}$ & $\mathbf{1 2 4 1 3 7 . 4}$ & $\mathbf{1 0 3 2 9 5 . 8}$ \\
\hline 38 & 1.08 & 3 & 14.2 & 164386.5 & 134340 & 118754.2 \\
\hline
\end{tabular}

carga máxima considerada para o carteiro foi de $\alpha . D_{G}=$ fator de aumento . demanda média do grupo de CEP5 (terceira coluna). Utilizou-se apenas 1 semente para cada grupo de CEP5. A quantidade de carga que será transportada por carteiro, determinada pelo algoritmo de clusters, é indicada na segunda coluna.

Os 13 distritos postais obtidos para este teste estão ilustrados na Figura 5 a seguir.

A Proposta 1 tem por objetivo fazer com que o carteiro possua seu DP com a menor quantidade de CEP5. Para o teste 3 cada DP obtido possui 3 códigos de CEP no máximo. E para a triagem, é reduzido, consideravelmente, o volume de objetos manipulados, pois 4 carteiros são necessários para a triagem de 3 CEP5's, 2 carteiros para 1 CEP5, 4 carteiros para 2 CEP5's e 3 carteiros para 2 CEP5's.

\subsection{Respostas para a Fase II - Roteamento de Cada DP's}

Para determinar a seqüência dos pontos de parada dos distritos postais foram aplicados separadamente os algoritmos: inserção econômica, savings de Clarke e Wright, sweep e o do carteiro chinês aos melhores resultados da Fase I, para cada uma das propostas e abordagens. Após a utilização dos algoritmos de roteamento de nós foi utilizado o algoritmo de melhoria 2-opt. Os testes para os quais foram realizados o roteamento foram os de números $3,17,23$ e 37 . Os valores obtidos para estes testes estão no Quadro 8.

Na Figura 6 tem-se a sequiência do trajeto para uma parte da região abrangida pelo DP2 para a proposta 2 , abordagem rua, teste 3 , aplicando 
Quadro 7 - Solução para a fase I, proposta 1, abordagem rua, fornecida pelo teste 3

\begin{tabular}{|c|c|c|c|c|c|c|}
\hline $\begin{array}{c}\text { Distrito } \\
\text { Postal }\end{array}$ & $\begin{array}{c}\text { Carga } \\
\text { Transportada } \\
\text { por Carteiro }\end{array}$ & $\begin{array}{c}\text { Carga } \\
\text { Máxima }\end{array}$ & $\begin{array}{c}\text { Semente } \\
\text { Associada }\end{array}$ & $\begin{array}{c}\text { Distância } \\
\text { MdepCW e } \\
\text { Ajuste }\end{array}$ & $\begin{array}{c}\text { Distância } \\
\text { Inserção } \\
\text { Econômica }\end{array}$ & $\begin{array}{c}\text { Distância } \\
\text { Melhoria }\end{array}$ \\
\hline 1 & 0.947914 & 1.118225 & 1 & 4587.64 & 5726.85 & 3703.63 \\
\hline 2 & 1.097331 & 1.118225 & 1 & 6777.43 & 4973.46 & 4815.95 \\
\hline 3 & 1.072368 & 1.118225 & 1 & 4720.38 & 4557.65 & 4399.04 \\
\hline 4 & 1.102103 & 1.118225 & 1 & 3481.14 & 3721.79 & 3242.24 \\
\hline 5 & 0.992408 & 1.072069 & 1 & 3655.03 & 3252.9 & 3459.19 \\
\hline 6 & 1.030364 & 1.072069 & 1 & 5953.26 & 5495.74 & 3100.15 \\
\hline 7 & 0.963278 & 1.061698 & 1 & 2412.43 & 2657.61 & 2655.58 \\
\hline 8 & 1.030092 & 1.061698 & 1 & 1785.82 & 2271.05 & 1526.2 \\
\hline 9 & 1.009671 & 1.061698 & 1 & 4293.92 & 4990.17 & 4444.25 \\
\hline 10 & 1.003366 & 1.061698 & 1 & 1739.2 & 1965.21 & 1622.54 \\
\hline 11 & 0.982496 & 1.024433 & 1 & 2828.57 & 2874.14 & 2436.91 \\
\hline 12 & 0.903681 & 1.024433 & 1 & 3381.59 & 3331.74 & 2841.93 \\
\hline 13 & 1.01316 & 1.024433 & 1 & 4663.87 & 5886.68 & 4592.1 \\
\hline Total & 13.14 & 13.93 & 1 semente & 50280.34 & 51705.04 & 42839.75 \\
\hline
\end{tabular}
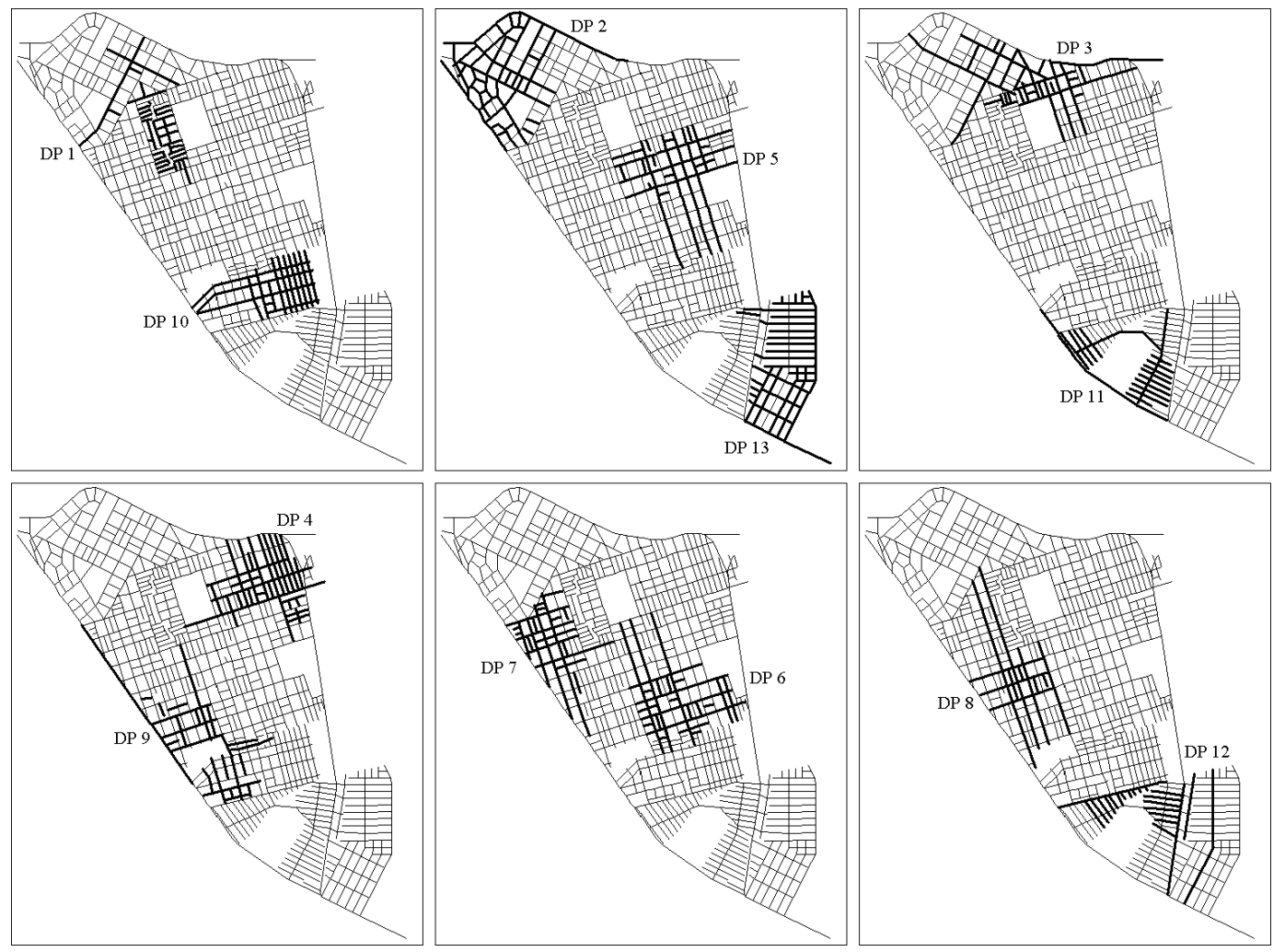

Figura 5 - Divisão do CDD em DP's para a fase I, proposta 1, abordagem rua, fornecida pelo teste 3 
Quadro 8 - Distâncias reais do trajeto dos roteiros para cada teste realizado para a fase II, de roteamento de cada DP

\begin{tabular}{|c|c|c|c|c|c|}
\hline Teste & Proposta & Abordagem & Algoritmo & $\begin{array}{l}\text { Distância Total } \\
\text { do CDD }\end{array}$ & $\begin{array}{c}\text { Distância Média } \\
\text { por carteiro }\end{array}$ \\
\hline \multirow{4}{*}{3} & \multirow{4}{*}{1} & \multirow{4}{*}{ rua } & Inserçãa & 223387.75 & 17183.67 \\
\hline & & & Savings & 224593.62 & 17276.43 \\
\hline & & & Sweep & 225641.60 & 17357.04 \\
\hline & & & Carteiro Chinês & 245707.93 & 18900.61 \\
\hline \multirow{4}{*}{17} & \multirow{4}{*}{1} & \multirow{4}{*}{ trecho } & Inserção & 216294.45 & 16638.03 \\
\hline & & & Savings & 216342.64 & 16641.74 \\
\hline & & & Sweep & 220419.74 & 16955.36 \\
\hline & & & Carteiro Chinês & 221064.40 & 17004.95 \\
\hline \multirow{4}{*}{23} & \multirow{4}{*}{2} & \multirow{4}{*}{ rua } & Inserção & 225996.50 & 17384.34 \\
\hline & & & Savings & 225748.00 & 17365.23 \\
\hline & & & Sweep & 234142.77 & 18010.98 \\
\hline & & & Carteiro Chinês & 247167.72 & 19012.90 \\
\hline \multirow{4}{*}{37} & \multirow{4}{*}{2} & \multirow{4}{*}{ trecho } & Inserçãa & 218927.25 & 16840.55 \\
\hline & & & Savings & 220881.58 & 16990.89 \\
\hline & & & Sweep & 228653.92 & 17588.76 \\
\hline & & & Carteiro Chinês & 223762.90 & 17212.53 \\
\hline
\end{tabular}

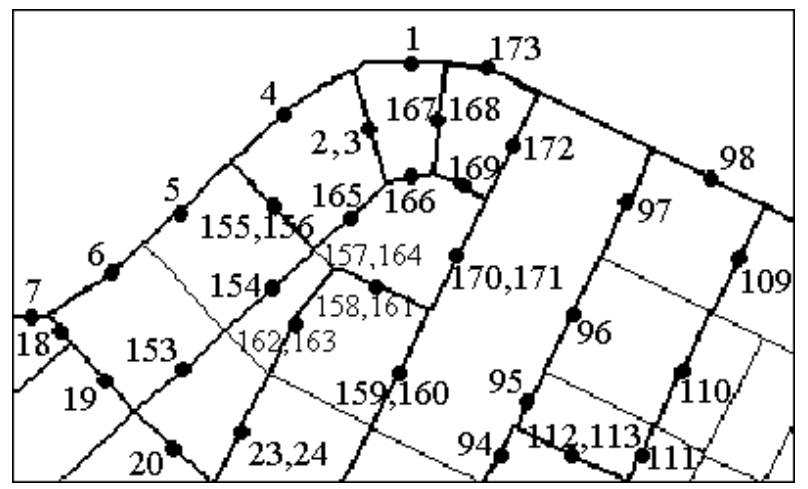

Figura 6 - Seqüência do trajeto do DP2 para a proposta 2, abordagem rua, teste 3, aplicando o algoritmo de inserção econômica

o algoritmo de inserção econômica. O primeiro ponto da rota está identificado pelo número 1 e o último pelo número 173. Os pontos de parada e os arcos onde existem entregas estão identificados por pontos e traços fortes. Dois números indicados sobre o mesmo ponto de parada significa que o carteiro faz o trajeto em $\mathrm{U}$, ou seja, percorre um lado da rua e retorna pelo outro.

\section{Conclusões}

Com base nos vários testes realizados foi possível estabelecer um procedimento para determinar a divisão de uma região e seu roteamento, em especial, para atender a situação atual dos Correios - que consiste em dividir a região do CDD em sub-regiões (DP's), utilizando 
a proposta de divisão da região dentro dos grupos de CEP's, designando uma rua inteira a somente um carteiro.

A solução sugerida para a situação atual dos Correios é utilizar a resposta obtida pelo teste de número 3 , utilizando para carga máxima de cada carteiro o valor de $\alpha . \mathrm{D}_{\mathrm{G}}=$ (1.06. demanda média do grupo de CEP5) e utilizar para o roteamento nos distritos postais o algoritmo de inserção econômica, pois foi o que forneceu os melhores resultados. Para cada cluster obtido na fase I, a distância euclidiana, em média, foi de $3295 \mathrm{~km}$ (distância total / quantidade de carteiros), e varia- ção da carga para entrega para cada DP, comparando a menor delas em relação a maior foi de $15 \%$; e para a fase II, a distância real de percurso foi de $17183 \mathrm{~km}$, em média, para cada carteiro.

Embora outros testes tenham fornecido distâncias um pouco menores, este é o que se mostra mais interessante para ser aplicado à situação atual dos Correios pois tende a facilitar significativamente o processo de triagem dos objetos, reduzindo o tempo dispendido nesta tarefa e conseqüentemente ganha-se mais tempo para executar o trabalho externo de entrega das correspondências.

\section{Referências Bibliográficas}

BARBOSA, V.C.: "Redes neuronais e simulated annealing como ferramentas para otimização combinatória”. Investigación Operativa, v. 1, n. 2 , p. $125-142,1989$.

BELTRAMI, E.J. \& BODIN, L.D.: "Networks and vehicle routing for municipal waste collection". Networks, v. 4, p. 65-94, 1972.

BERTHOLDI COSTA, D.M.: Aplicação de algumas Técnicas da Pesquisa Operacional na Otimização dos Serviços Postais. Curitiba, 1997. Dissertação de Mestrado, Universidade Federal do Paraná.

BEZERRA, O.B.: Localização de postos de coleta para apoio ao escoamento de produtos extrativistas - um estudo de caso aplicado ao babaçu. Florianópolis, 1995. Dissertação (Mestrado em Engenharia) - Departamento de Engenharia de Produção e Sistemas, Universidade Federal de Santa Catarina.

BODIN, L.; GOLDEN, B.; ASSAD, A. \& BALL, M.: Routing and Scheduling of vehicles and crews: the state of the art. Special Issue. England: Pergamon Press, 1983.

BODIN, L.D. \& KURSH, S.J.: “A computer-assisted system for the routing and scheduling of street sweepers". Operations Research, v. 26, n. 4, p. 525-537, july/aug, 1978.

CAMAROTTI, G.: "Rapidez extraviada". Revista Veja, São Paulo, n. 11, p. 68-70, mar, 1997.

CLARK, R.M. \& GILLEAN, J.I.: "Solid waste collection: a case study". Operational Research Quarterly, v. 28, n. 4, p. 795-806, 1977.
CLARKE, G. \& WRIGHT, J.W.: "Scheduling of vehicles from a central depot to a number of delivery points". Operations Research, v. 12, n. 4, p. 568-581, july/aug, 1964.

COLORNI, A.; DORIGO, M.; MAFFIOLI, F.; MANIEZZO, V. et al.: "Heuristics from nature for hard combinatorial optimization problems". International Transactions in Operational Research, v. 3, n. 1, p. 1-21, 1996

CHRISTOFIDES, N.: Graph theory - an algorithmic approach. New York: Academic Press Inc, 1975.

DAGANZO, C.F.: "The distance traveled to visit Noints with a maximum of $C$ stops per vehicle: an analytic model and an application". Transp. Science, v. 18, p. 331-350, 1984.

EDMONDS, J. \& JOHNSON, E.L.: "Matching, Euler tours and the chinese postman". Mathematical Programming, v. 5, p. 88-124, 1973.

FEO, T.A. \& RESENDE, M.G.C.: "Greedy randomized adaptive search procedures". Journal of Global Optimization, p. 1-27, 1995.

FLOYD, R.W.: “Algorithm 97: shortest path". Communications of the Association for Computing Machinery, v. 5, p. 345, 1962.

GENDREAU, M.G.; HERTZ, A. \& LAPORTE, G.: "A tabu search heuristic for the vehicle routing problem". Publication \#777, Centre de Recherche sur les Transports, Université de Montréal, 1991.

GILLETT, B.E. \& MILLER, L.R.: "A heuristic algorithm for the vehicle-dispatch problem". Ops Res., v. 22, p. 340-349, 1974. 
GOLDEN, B.; BODIN, L.; DOYLE, T. \& STEWART JR, W.: "Approximate traveling salesman algorithms". Operations Research, v. 28, n. 3, parte II, p. 694-711, may/june, 1980.

GOLDEN, B.L.; MAGNANTI, T.L. \& NGUYEN, H.Q.: "Implementing vehicle routing algorithms". Networks, v. 7, p. 113-148, 1977.

GLOVER, F.: “Tabu search, Part I". ORSA Journal on Computing, v. 1, n. 3, p. 190-206, 1989.

GLOVER, F.: "Tabu search, Part II". ORSA Journal on Computing, v. 2, p. 4-32, 1990.

GRACIOLLI, O.D.: Dimensionamento e otimização de sistemas de distribuição física de produtos um enfoque contínuo. Florianópolis, 1996. Exame de qualificação para doutoramento, Universidade Federal de Santa Catarina.

LEVY, L. \& BODIN, L.: "Scheduling the postal carriers for the United States postal service: an application of arc partitioning and routing". In: GOLDEN, B.L. \& ASSAD, A.A. (Eds.) Vehicle routing: Methods and studies. North-Holland: Elsevier Science Publishers B. V., p. 359-394, 1988.

LIN, S. \& KERNIGHAN, B.W.: "An effective heuristic algorithm for the travelling salesman problem.” Op. Res., v. 21, p. 498-516, 1973.

MAYERLE, S.F.: Um algoritmo genético para solução do problema do caixeiro viajante. Trabalho interno. Florianópolis: UFSC, 1996.
MULVEY, J.M. \& BECK, M.P.: "Solving capacitated clustering problems". European Journal of Operational Research. v 18, p. 339-348,1984.

NOGUEIRA, C.H.C.; MAGALHÃES, I.B.; IZU, M. et al.: O problema da coleta do lixo urbano: uma solução via programação matemática. Trabalho interno. Rio de Janeiro: Instituto de Matemática UFF, 1989.

PARAIBA, L.C.; FERNANDES, J.F.R. \& ANDO, A.S.: Um algoritmo heurístico de construção paralela para o problema do M-caixeiro viajante. Trabalho interno. Campinas: UNICAMP, 1990.

RIBEIRO, C.: Busca tabu. VII Congresso latinoibero americano de investigacion de operaciones e ingenieria de sistemas, Chile, 1994.

SOSA, N.G.M. \& FRANÇA, P.M.: Um estudo de heurísticas para o problema de agrupamento capacitado aplicando busca tabu. XXVIII Simpósio Brasileiro de Pesquisa Operacional, Rio de Janeiro, 1996.

TILLMAN, F.A. \& CAIN, T.M.: “An upperbound algorithm for the single and multiple terminal delivery problem". Management Science, v. 18, n. 11, p. 664-682, july, 1972.

WATERS, C.D.J.: "A solution procedure for the vehicle scheduling problem based on iterative route improvement". Journal of the Operational Research Society, v. 38, n. 9, p. 833-839, 1987.

\title{
OPERATIONS RESEARCH TECHNIQUES APPLIED IN THE POST SERVICES
}

\begin{abstract}
A solution is proposed for the problem of correspondence delivery done by the post service system, using some Operation Research techniques. Having in mind that the delivery and its preceding phases (selection and sorting) are manually made, there is a necessity to optimise these procedures and that is possible reorganising the postmen's delivery areas. To do that, this problem was treated as a Vehicle Routing Problem. Many classic algorithms were used, at first to determine the postmen's delivery area, called postal districts, and then to establish the mail delivery route, using in this phase the real distance among the delivery points. Many tests were done changing the algorithms and initial parameters, and the results were compared using the total distances and the computational time spent, in order to determine the algorithms with the best performance.
\end{abstract}

Key words: vehicle routing problem, clusters and optimal routes. 